\title{
Investigation on the performance of air plasma sprayed thermal barrier coating with Lu/Hf-doped NiAl bond coat
}

DOI:

10.1016/j.surfcoat.2019.01.005

\section{Document Version}

Accepted author manuscript

Link to publication record in Manchester Research Explorer

\section{Citation for published version (APA):}

Zhao, C., Luo, L., Lu, J., Zhao, X., Wang, X., Guo, F., \& Xiao, P. (2019). Investigation on the performance of air plasma sprayed thermal barrier coating with Lu/Hf-doped NiAl bond coat. Surface and Coatings Technology, 360, 140-152. https://doi.org/10.1016/j.surfcoat.2019.01.005

\section{Published in:}

Surface and Coatings Technology

\section{Citing this paper}

Please note that where the full-text provided on Manchester Research Explorer is the Author Accepted Manuscript or Proof version this may differ from the final Published version. If citing, it is advised that you check and use the publisher's definitive version.

\section{General rights}

Copyright and moral rights for the publications made accessible in the Research Explorer are retained by the authors and/or other copyright owners and it is a condition of accessing publications that users recognise and abide by the legal requirements associated with these rights.

\section{Takedown policy}

If you believe that this document breaches copyright please refer to the University of Manchester's Takedown Procedures [http://man.ac.uk/04Y6Bo] or contact uml.scholarlycommunications@manchester.ac.uk providing relevant details, so we can investigate your claim.

\section{OPEN ACCESS}




\title{
Investigation on the performance of air plasma sprayed thermal barrier coating with $\mathrm{Lu} / \mathrm{Hf}$-doped $\mathrm{NiAl}$ bond coat
}

\author{
Chunshan Zhao
}

School of Materials Science and Engineering, Shanghai Jiao Tong University, Shanghai 200240, China Lirong Luo

School of Materials Science and Engineering, Shanghai Jiao Tong University, Shanghai 200240, China

$$
\text { Jie } \mathrm{Lu}
$$

School of Materials Science and Engineering, Shanghai Jiao Tong University, Shanghai 200240, China Xiaofeng Zhao

School of Materials Science and Engineering, Shanghai Jiao Tong University, Shanghai 200240, China Xin Wang Konca Solar Cells Co., Ltd, Wuxi 214000, China Fangwei Guo

School of Materials Science and Engineering, Shanghai Jiao Tong University, Shanghai 200240, China

$$
\text { Ping Xiao }
$$

School of Materials, University of Manchester, MSS Tower, Manchester M13 9PL, United Kingdom

\footnotetext{
*Corresponding author: Xiaofeng Zhao

Email: xiaofengzhao@sjtu.edu.cn; Tel: +86-21-54742561; Fax: +86-21-54742561
} 


\begin{abstract}
The durability of air plasma sprayed (APS) thermal barrier coatings (TBCs) with NiAl bond coats with/without Lu/Hf doping was investigated under thermal cycling at $1150{ }^{\circ} \mathrm{C}$, and compared with the conventional NiCoCrAlY sample. The oxidation kinetics, microstructure evolution and surface roughness of the bond coats were characterized and the cycle lifetime measured. The TBC with the NiAl bond coat exhibited a lifetime of $456 \mathrm{~h}$, which was comparable with the NiCoCrAlY sample (480 h). By contrast, the NiAl-Lu/Hf TBC showed a two or three fold enhanced lifetime, i.e., $840 \mathrm{~h}$ and $1248 \mathrm{~h}$, respectively. It is proposed that the enhanced lifetime is a result of combination of decreasing of the oxidation rate and retention of the interfacial toughness. The APS NiAl bond coat with $\mathrm{Lu} / \mathrm{Hf}$ doping has a great potential for TBCs designed for higher temperature applications.
\end{abstract}

Keywords: Thermal barrier coatings (TBCs), Bond coat, Air plasma spray (APS), $\mathrm{NiAl}$, lifetime

\title{
1 Introduction
}

Thermal barrier coatings (TBCs) are commonly used in the hot-sections of gas-turbine engines to protect the superalloy components from high temperature and improve the efficiency of the engines [1-4]. A typical TBC system consists of a ceramic top coat and an intermediate metallic bond coat deposited on a superalloy substrate. The bond coat is arguably the most crucial component of the TBC system, which influences the TBC durability by multiple ways [5-7]. Firstly, its chemistry and microstructure determine the structure, growth rate and adherence of the thermally grown oxide (TGO) formed as it oxides. Secondly, system performance is linked to its creep and yield characteristics $[6,8]$. The conventional bond coat is $\operatorname{MCrAlY}(\mathrm{M}: \mathrm{Ni}$, Co or both), usually consisting of two phases ( $\beta$-NiAl and either $\gamma$-Ni solid solution or $\gamma^{\prime}-\mathrm{Ni}_{3} \mathrm{Al}$ ), which can realize long-term operation below $1100{ }^{\circ} \mathrm{C}$. However, as the 
turbine-inlet temperature continues to rise, this material cannot fully meet the demand due to accelerated thickening and cracking of the TGO that finally results in TBC failure $[9,10]$.

Recently, $\beta$-NiAl, considered as a promising candidate material replacement for MCrAlY, has attracted increasing attention due to its good isothermal oxidation resistance, high strength, high melting point $\left(1638{ }^{\circ} \mathrm{C}\right)$, low density and low cost [11-13]. However, the TGO formed on $\mathrm{NiAl}$ spalls readily during thermal cycling due to its poor adherence, which impedes its applications. To improve the TGO adherence, a thirdly additional element is essential, particularly reactive elements (REs), such as Hf, Zr, Y [14-18]. These traditional REs, as well as their oxide dispersions in Ni-Al alloys or coatings have been extensively studied and shown that trace RE addition $(0.05 \sim 0.5$ at.\%) can significantly improve the TGO adherence. More recently, as a broader effort to seek a potential doping element which is more effective than the existing system, the effect of lanthanides was investigated. For example, Guo et al. $[10,19]$ reported that Dy significantly improved the TGO adherence of NiAl bond coat in electron beam physical vapor deposited (EB-PVD) TBCs. It was also reported that $\mathrm{Lu}$ could substantially improve the oxidation resistance of NiAl alloy by preventing S segregation and void formation at the TGO/alloy interface [20].

Plasma spray, such as air plasma spray (APS), as an economic and versatile method, is widely applied in the fabrication of metallic bond coats (e.g., MCrAlY) [5, 21]. As $\mathrm{NiAl}$ is a very stable compound, APS method is also considered for its deposition. However, NiAl bond coat deposited by APS has been rarely reported [22, 23]. Compared with MCrAlY, deposition of NiAl by APS is more challenging. Firstly, the high content of oxide inclusions formed during high temperature spraying deteriorates the oxidation performance of NiAl. Secondly, the brittleness of NiAl at ambient temperature may affect the adherence with superalloy substrate. However, as will be shown in this work, with optimized processes and parameters, the TBC with Lu/Hf-doped NiAl bond coat show significantly enhanced durability compared with that with the conventional NiCoCrAlY bond coat. 
The objective of this work is to develop an economic, high performance bond coat applied in industrial gas turbines. For this purpose, APS TBCs with different bond coats, i.e. NiAl, NiAl-Lu and NiAl-Hf, were prepared using the powder made through arc-melting and ball milling. In addition, the TBC with a conventional NiCoCrAlY bond coat was also fabricated for comparison. All the samples were tested under the same condition (thermal cycling at $1150{ }^{\circ} \mathrm{C}$ ) and the TBCs lifetimes were evaluated based on the spallation degree after thermal cycling. The oxidation kinetics, microstructure evolution and surface roughness of the bond coats were investigated and discussed in related to final failure of the TBCs.

\section{Experiment}

\subsection{Materials and sample preparation}

In this work, the $\mathrm{NiAl}$ bond coat is sto ichiometric (50:50 in atomic ratio), and the two RE-doped ones are Ni-49.7Al-0.3 Hf and Ni-49.7Al-0.3 Lu (all in at.\%). The materials were obtained by arc-melting, and then annealed at $1200{ }^{\circ} \mathrm{C}$ for $100 \mathrm{~h}$ in argon flow to homogenize the composition. The necessary powders for coating deposition were obtained by crushing and milling the bulk obtained from arc-melting in a planetary ball mill, and then sieved to the range of $40-110 \mu \mathrm{m}$.

A supersonic air plasma spray (SAPS) system (Model: HEPJ- II ; National Key Laboratory For Remanufacturing, Beijing, China) was used for coating deposition. The feedstock powder was radially injected into the plasma jet by an internal injection port with an inlet diameter of $2 \mathrm{~mm}$ inside a laval nozzle [24, 25]. A commercial superalloy DZ125L (9Cr10Co7W2Mo5Al3.5 Ti4 Ta, in wt.\%, balanced by Ni) with a thickness of $4 \mathrm{~mm}$ was used as the substrate. The substrate was ultrasonically cleaned, grit blasted $\left(\mathrm{Al}_{2} \mathrm{O}_{3}, 30 \#\right)$ and then placed in the APS system for overlaying a metallic bond coat. Afterwards, a top coat of commercial 8 wt.\% YSZ (Metco 204B-NS, Sulzer Metco) was overlaid. The target thicknesses of the top coat and bond coats were $200 \mu \mathrm{m}$ and $135 \mu \mathrm{m}$ respectively. The spray parameters are given in Table 1. For comparison, a reference sample with a commercial NiCoCrAlY (17Cr23Co12A10.5Y, 
in wt.\%, balanced by Ni, Amdry 365-2, Sulzer Metco) bond coat with the same thickness of the NiAl bond coat was also prepared, using the identical spay parameters. To density the bond coats and get chemical bonding to the substrates, a vacuum $\left(10^{-4}-10^{-3} \mathrm{~Pa}\right)$ heat treatment at $1100{ }^{\circ} \mathrm{C}$ for $4 \mathrm{~h}$ was employed for all samples.

Table 1 Air plasma spray parameters for the bond coat and YSZ top coat deposition

\begin{tabular}{ccc}
\hline Spray parameters & Bond coat & YSZ coating \\
\hline Spray distance (mm) & 90 & 100 \\
Arc current (A) & 400 & 425 \\
Voltage (V) & 148 & 145 \\
Ar flow rate (SLPM) & 91.5 & 111 \\
H$_{2}$ flow rate (SLPM) & 15.9 & 19 \\
Carrier gas flow rate (SLPM) & 5 & 5.8 \\
Gun speed (mm/s) & 800 & 800 \\
\hline
\end{tabular}

SLPM=Standard litres per minute

\subsection{The rmal cycling test}

The samples were cut into plates with a dimension of $15 \times 15 \mathrm{~mm}^{2}$. To examine the durability of the TBCs, a 24-hour thermal cycling was conducted at $1150{ }^{\circ} \mathrm{C}$ in a chamber furnace at atmosphere environment, which consisted of 10-minute heating-up to $1150{ }^{\circ} \mathrm{C}, 23.5$-hour dwelling at $1150{ }^{\circ} \mathrm{C}$ and followed by 20 -minute air-cooling [24, 26]. The samples were removed after each cycle inspected for integrity and reinserted into the furnace. For each TBC system, twelve sliced pieces were used, six were subjected to failure (donated as the spallation of $20 \%$ of the $\mathrm{TBC}$ ), and the others were removed after required cycles for characterization of microstructure evolution.

\subsection{Cha racterization}

The morphology and microstructure of the samples were observed using an optical microscope (BX51M, Olympus) and a scanning electron microscope (SEM, Inspect F50, FEI). The phase composition and element distribution were analyzed by an energy-dispersive spectroscope (EDS, Rontec). 
The TGO thickness (including $\mathrm{Al}_{2} \mathrm{O}_{3}$ and spinel oxide) was examined using backscattered SEM (BSE) images taken on the polished cross-sections. The average thickness was obtained by measurements at 50 equidistance points distributed over the length of the cross-sections with a step size of $20 \mu \mathrm{m}$.

The area fraction of the internal oxide within the bond coat was quantified by image analysis using ImageJ software [27]. All the images were taken on the cross-sections in BSE mode, and at least six randomly selected areas $\left(\sim 135 \times 300 \mu \mathrm{m}^{2}\right)$ were analyzed for each sample. The TGO layer at the bond coat/TBC interface was not taken into account in measurement of the internal oxide.

The top coat/TGO interface roughness was quantified by image analysis of cross-sectional SEM micrographs. For roughness analysis, the coordinates of the top coat/TGO interface, $y(x)$, for each cross-section were recorded at 5-um intervals along the $\mathrm{x}$-axis and leveled by zeroing the mean height, $\bar{y}=0$. The detailed description of this method can be found elsewhere [28]. The interface roughness was characterized by the commonly used parameter, i.e., arithmetic average height, Ra. For each specimen, five images with a magnification of $2000 \times$ were analyzed.

\section{Results}

\subsection{Microstructure evolution of the bond coats}

Fig. 1 shows the microstructures of the as-received TBCs after vacuum heat treatment. The thicknesses of the bond coats $(\sim 135 \mu \mathrm{m})$ and top coat $(\sim 200 \mu \mathrm{m})$ for all the samples were roughly the same. The porosity of the top coat was $9.3 \pm 2.1 \%$, relatively lower than typical APS ones (15 25\%) [1], due to the higher particle fight velocity of the SAPS system $(>400 \mathrm{~m} / \mathrm{s})$ than typical APS systems $(130-300 \mathrm{~m} / \mathrm{s})[25,29]$. All the bond coats exhibited a splat microstructure as typical APS coatings, which were characterized by the presence of oxide stringers and voids at the splat boundaries [30]. Fig. 2 presents the detailed observations of the bond coats and elemental mapping results. It is visible that Lu primarily situated within the grains as gra nular precipitates 


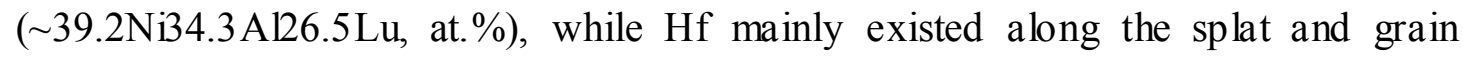
boundaries $(\sim 43.5 \mathrm{Ni} 28.6 \mathrm{Al} 27.9 \mathrm{Hf}$, at.\%). Those observations were consistent with previous studies on the Lu/Hf doped-NiAl alloys [20]. The NiAl(-Lu/Hf) bond coat revealed a single $\beta$ phase $(\sim 48 \mathrm{~A} 152 \mathrm{Ni}$, at. $\%)$, while the $\mathrm{NiCoCrAlY}$ bond coat consisted of two phases, where the bright contrast corresponds to the $\gamma$ matrix phase $(\sim 26 \mathrm{Cr} 27.7 \mathrm{Co} 10.1 \mathrm{Al} 6 \mathrm{Ni} 0.2 \mathrm{Y}$, at. $\%)$ and the gray contrast the $\beta$ phase ( 5.2Cr10.4Co38.7A145.3Ni0.4Y, at.\%).
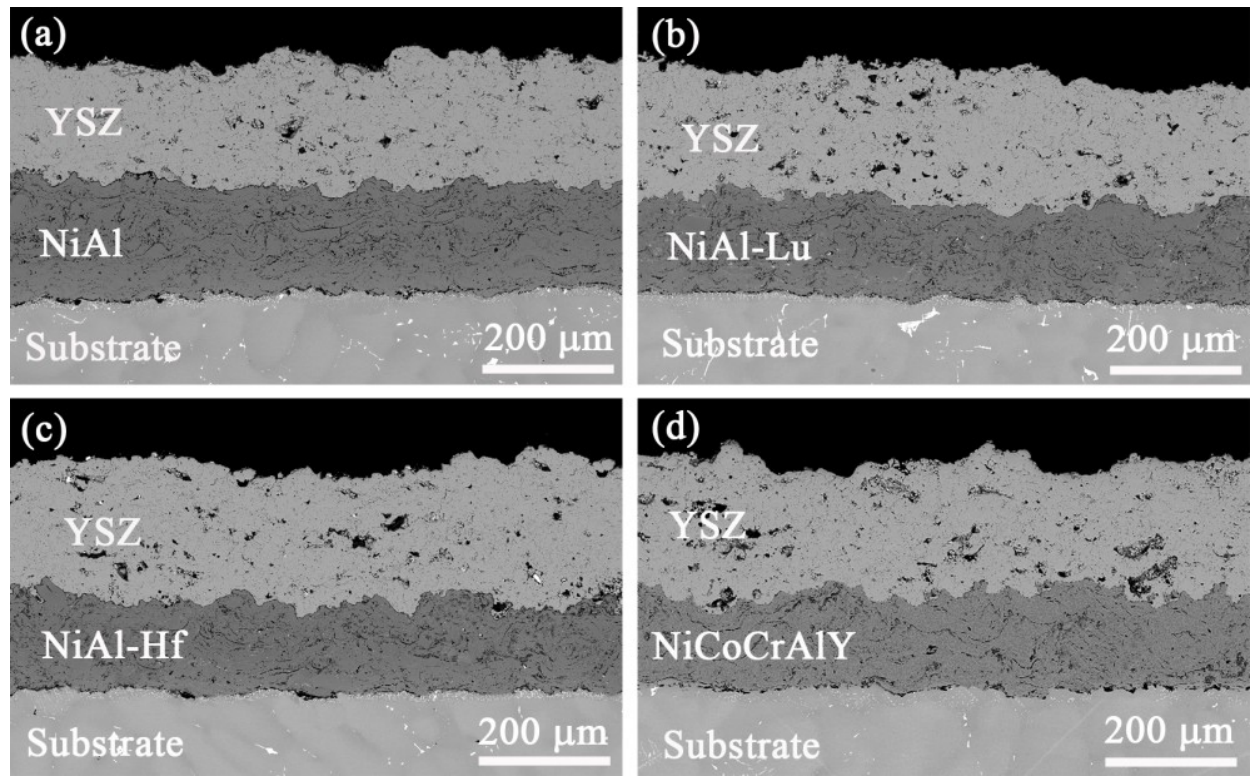

Fig. 1 Cross-sectional micrographs of the as-received TBCs with different bond coats after vacuum heat treatment: (a) NiAl, (b) NiAl-Lu, (c) NiAl-Hfand (d) NiCoCrAlY. Fig. 3 presents the microstructures of the bond coats and elemental mappings after 8 thermal cycles at $1150{ }^{\circ} \mathrm{C}$. The chemical compositions of the existed phases in the bond coats were statistically analyzed by EDS, as given in Table 2. During thermal exposure, oxidation occurred not only at the bond coat/top coat interface (termed as "TGO"), but also at the open pores between the poorly melted splats within the bond coat (termed as "internal oxidation") [27,31]. The oxidation of the bond coat resulted in Al depletion, which was also promoted by interdiffusion between the bond coat and superalloy substrate due to the composition gradient [32-34]. As a result, phase transformation occurred in the bond coat, i.e., from Al-rich $\beta$ phase to Ni-rich $\gamma$ or $\gamma^{\prime}$ $\left(\mathrm{Ni}_{3} \mathrm{Al}\right)$ phase. 

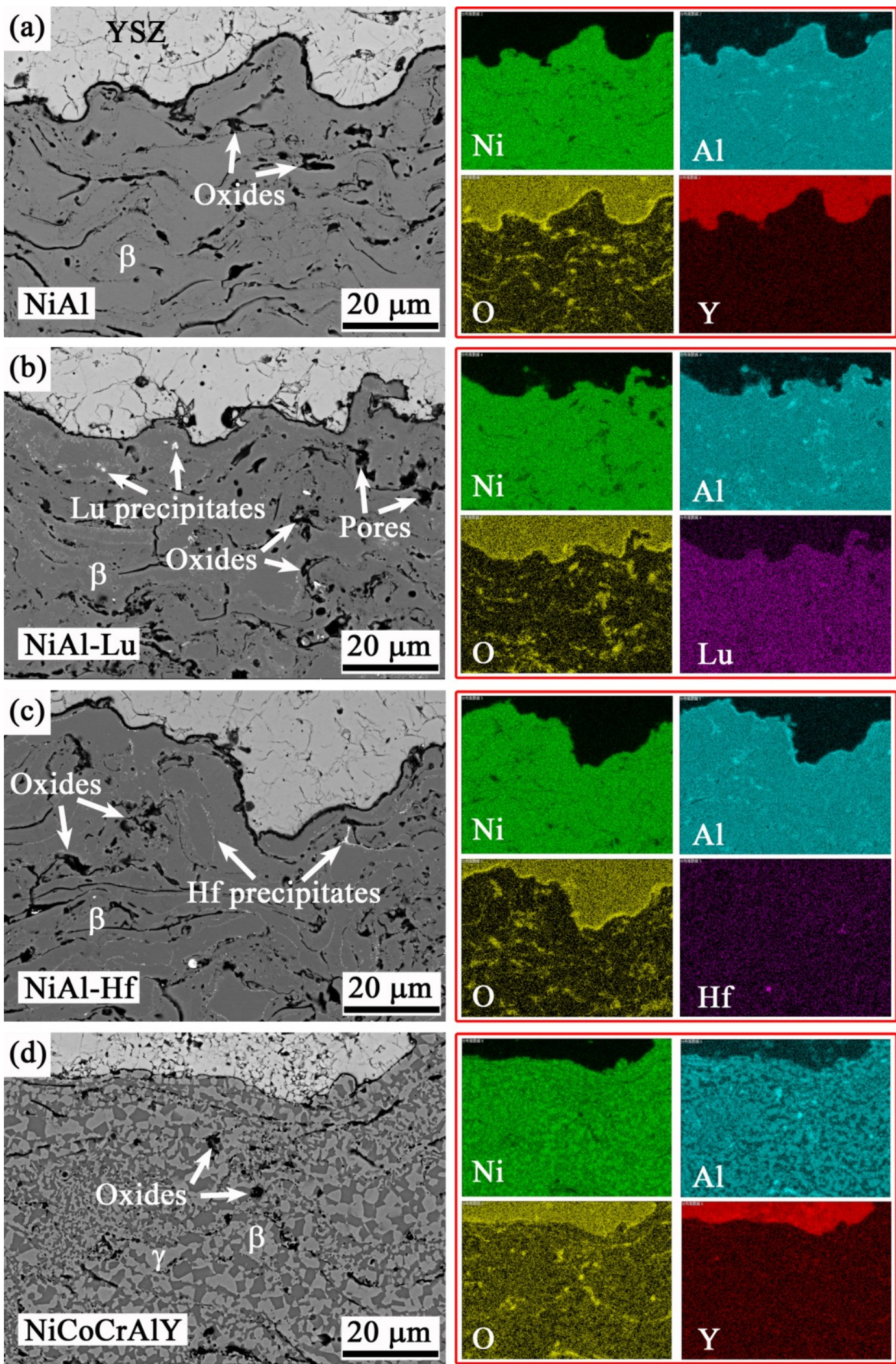

Fig. 2 Microstructures of the bond coats after vacuum heat treatment: (a) NiAl, (b) NiAl-Lu, (c) NiAl-Hf and (d) NiCoCrAlY. The images on the right are the corresponding elemental mapping results for the areas shown in the left images. 

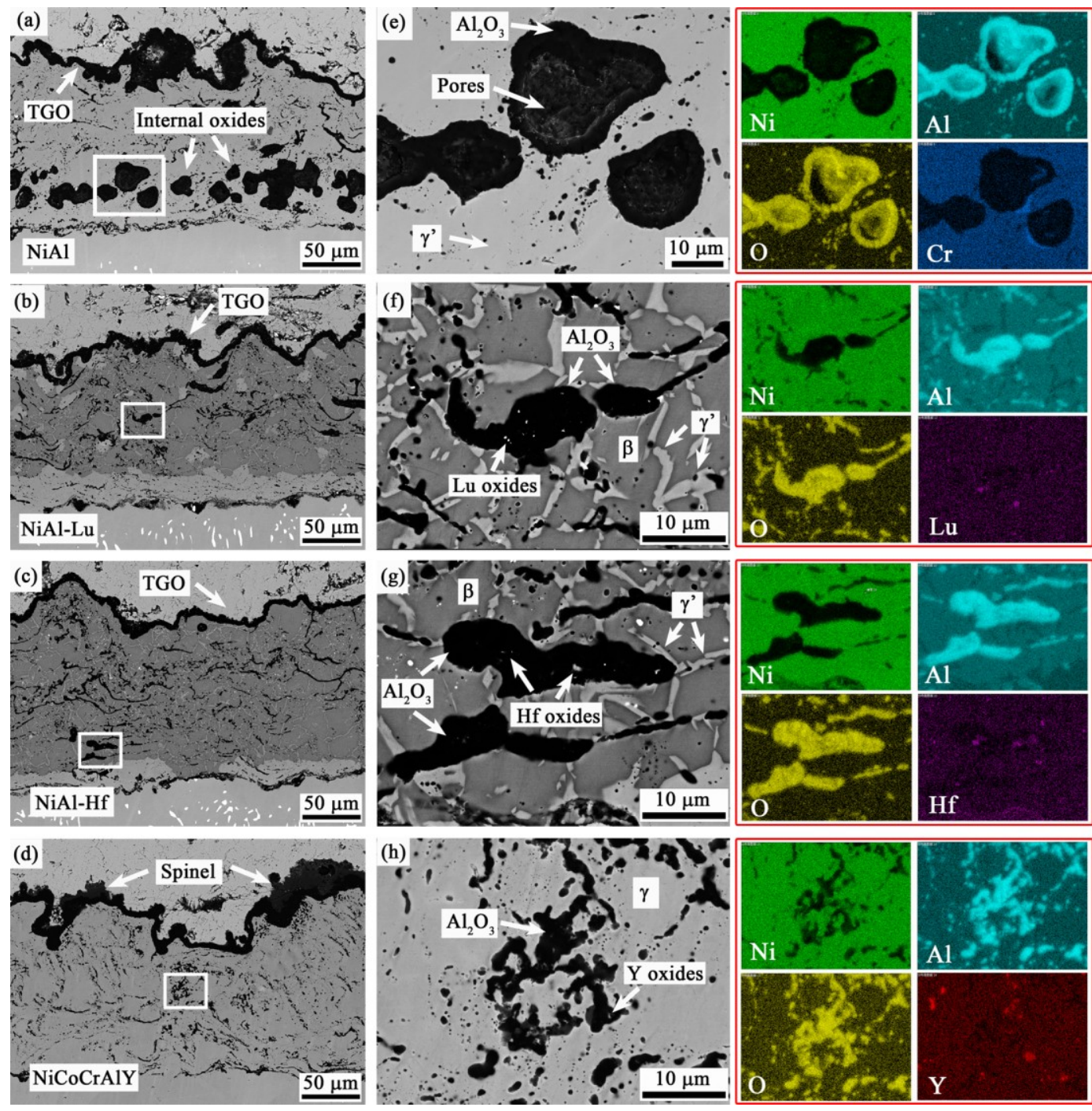

Fig. 3 Cross-sectional micrographs showing the microstructures of the bond coats after 8 cycles at $1150{ }^{\circ} \mathrm{C}$ : (a) NiAl, (b) NiAl-Lu, (c) NiAl-Hf and (d) NiCoCrAlY, and (e-h) are the correspond ing enlarged images of the areas marked by white boxes in the left images. The elemental mapping results for the areas in (e-h) were also given in the right images.

In the as-received state, only $\beta$ phase existed in the $\mathrm{NiAl}(-\mathrm{Lu} / \mathrm{Hf})$ bond coat (Fig. 2), while $\gamma^{\prime}$ phase appeared after thermal cycling (Fig. 3). As shown in Fig. 3a and e, after 8 thermal cycles, $\beta$ phase in the NiAl bond coat had almost transformed to $\gamma$ ' phase. However, for the NiAl-Lu/Hf bond coat, this phenomenon was not obvious. For example, $\gamma^{\prime}$ phase only existed along the grain or splat boundaries in the NiAl-Hf bond coat, except the diffusion zone near the bond coat/superalloy interface. Compared with the NiAl-Hf bond coat, the extent of phase transformation in the 
NiAl-Lu bond coat was slightly higher, where some large areas transformed to $\gamma^{\prime}$ phase. Such difference could be attributed to the difference in the oxidation behavior. In addition, the $\beta$ phase in the NiCoCrAlY bond coat changed to $\gamma$ phase due to its original low Al content, as clearly shown in Fig.3 and Table 2.

Table 2 Chemical compositions of the phases in the bond coats after 8 thermal cycles (in at. \%)

\begin{tabular}{cccccc}
\hline Sample & Phase & $\mathrm{Cr}$ & $\mathrm{Co}$ & $\mathrm{Al}$ & $\mathrm{Ni}$ \\
\hline \multirow{2}{*}{$\mathrm{NiAl}$} & $\beta$ & $5.5 \pm 0.8$ & $5.1 \pm 0.7$ & $30.2 \pm 2.4$ & $59.2 \pm 2.7$ \\
& $\gamma^{\prime}$ & $5.4 \pm 0.7$ & $5.9 \pm 0.6$ & $19.6 \pm 2.1$ & $69.1 \pm 3.0$ \\
$\mathrm{NiAl-Lu}$ & $\beta$ & $5.1 \pm 0.9$ & $4.7 \pm 0.7$ & $32.0 \pm 2.1$ & $58.2 \pm 2.5$ \\
& $\gamma^{\prime}$ & $4.5 \pm 0.6$ & $4.9 \pm 0.5$ & $23.8 \pm 1.6$ & $66.8 \pm 2.5$ \\
NiAl-Hf & $\beta$ & $4.6 \pm 0.5$ & $4.2 \pm 0.4$ & $32.4 \pm 2.0$ & $58.8 \pm 2.4$ \\
& $\gamma^{\prime}$ & $4.0 \pm 0.5$ & $4.3 \pm 0.3$ & $24.5 \pm 1.8$ & $67.2 \pm 2.6$ \\
NiCoCrAlY & $\gamma$ & $17.2 \pm 1.6$ & $19.1 \pm 1.4$ & $9.8 \pm 1.1$ & $53.9 \pm 2.1$ \\
\hline
\end{tabular}

\subsection{Inte rnal oxidation of the bond coats}

For plasma sprayed metallic bond coats exposed to high temperature, internal oxidation is an inevitable phenomenon, which may influence the durability of TBC systems $[27,30,35]$. As shown in Fig. 3, after 8 cycles, internal oxidation occurred in all the bond coats. Fig. 4 presents the internal oxidation behavior of the NiAl bond coat and the area fractions of the internal oxide for all the samples as a function of cycle number. For measurement, the TGO layer at the bond coat/top coat interface was not taken into account, and for simplicity, the "internal oxide fraction" refers to area fraction of the dark contrast areas including the oxide and possible pores within the bond coat $[27,30]$. Initially, all the bond coats included a certain amount of oxide and pores $(6 \sim 8 \%)$ due to in-flight oxidation during plasma spraying. It should be noted that the as-received bond coats were relatively denser than typical APS ones, mainly due to: (a) the higher particle flight velocity of the SAPS system, (b) densifying by the vacuum heat treatment [30]. For all the samples, the internal oxide fraction increased as the cycle number increased. The internal oxide fraction in the 
NiAl bond coat increased almost linearly as the cycle number increased, while approximately followed a parabolic law for the other bond coats. After 17 thermal cycles, the internal oxide fraction in the NiAl bond coat was up to $\sim 35 \%$, while that in the other bond coats were much lower (15 19 \%), which were in the order: NiAPNiCoCrAlY $>$ NiAl-Lu $>$ NiAl-Hf.
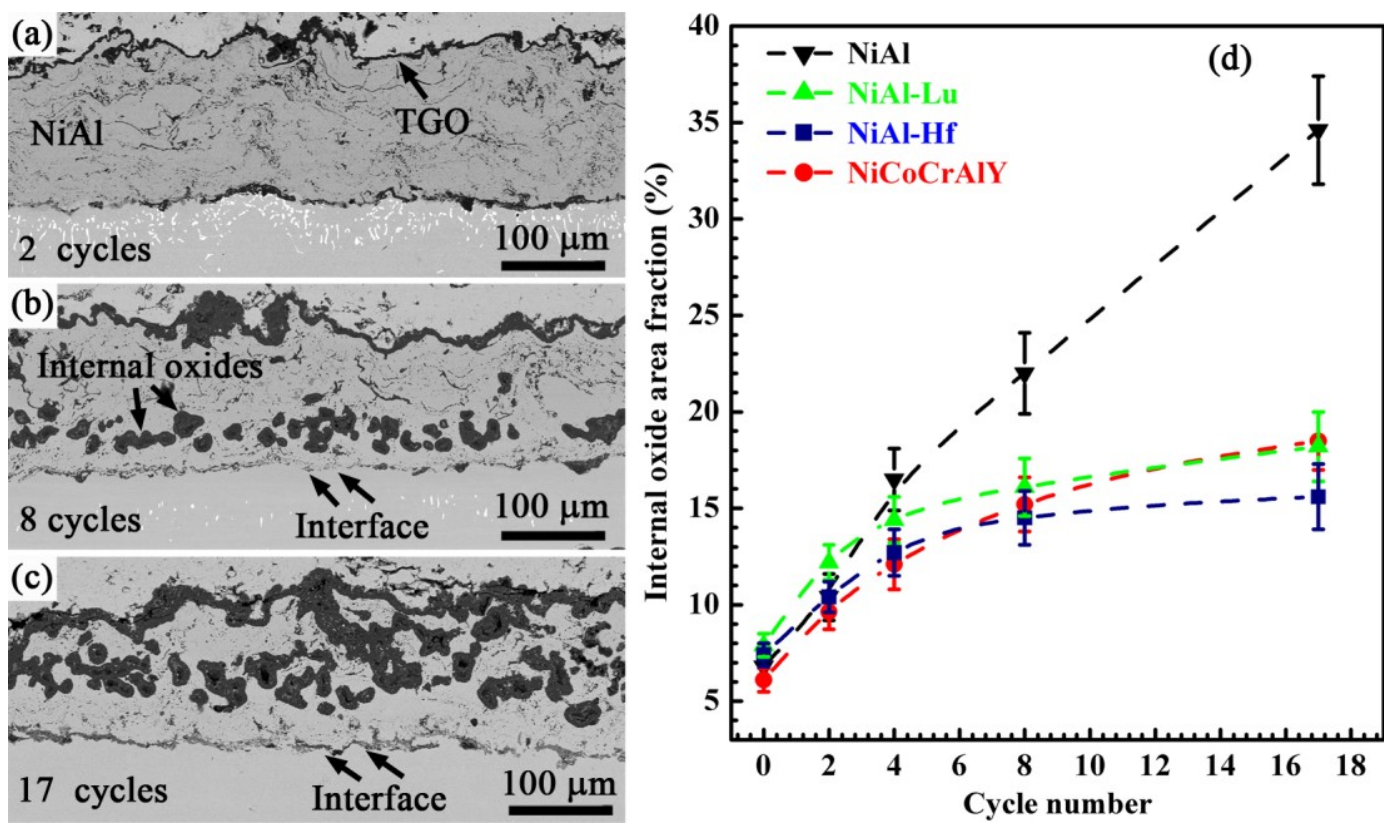

Fig. 4 Cross-sectional micrographs showing the internal oxidation behavior of the NiAl bond coat at $1150{ }^{\circ} \mathrm{C}$ after: (a) 2 cycles, (b) 8 cycles and (c) 17 cycles. (d) shows the area fractions of the internaloxide as a function of cycle number for all the bond coats.

For typical APS bond coats, internal oxide preferentially forms along the oxide stringers, with some randomly distributed areas of concentrated oxide at regions of multi-plat boundaries and smaller splattered splats [30], as well as the case for the $\mathrm{NiAl}-\mathrm{Lu} / \mathrm{Hf}$ and NiCoCrAlY bond coats. However, for the NiAl bond coat, a large amount of concentrated oxide formed during thermal cycling, which was responsible for its severest internal oxidation. As shown in Figs. 1 and 2, the microstructure of the bond coats were similar due to the identical preparation parameters, so the difference in the extent of internal oxidation should be attributed to the bond coat composition. As evidenced in Fig. 3 and 4, the internal oxide formed in the RE-containing bond coats (NiAl-Lu, NiAl-Hf and NiCoCrAlY) exhibited a dense microstructure with an 
amount of RE(Lu, Hf and Y)-rich oxide precipitates. However, the internal oxide in the NiAl bond coat showed a non-uniform microstructure with a lot of pores and cracks (Figs. 3e and 4). It is supposed that the severe internal oxidation of the NiAl bond coat was due to the crack generation in/around the oxide, which provided rapid transport paths for oxygen, leading to accelerated internal oxidation. The internal oxidation of the bond coat resulted in volume expansion, leading to generation of compressive growth stress in the oxide [27]. Upon cooling to room temperature, the oxide growth stress, accompanied with the mismatch stress of thermal expansion, could lead to crack generation in the oxide. Considering that $\mathrm{NiAl}$ is a brittle material at room temperature, cracks may even generate in the NiAl material around the internal oxide. For the RE-containing bond coats, as the internal oxide was slowly growing and adherent, cracks formation would not was greatly reduced. It reasonably suggests that RE could suppress the internal oxidation of bond coat by forming slowly growing and adherent oxide, as well as the instance for the TGO formed on the bond coat surface, which has been intensively reported [20, 36, 37].

\subsection{The TGO growth rate}

The TGO, formed at the bond coat/top coat interface, is widely believed to be a major factor on the durability of TBCs [1, 5, 38]. Previous studies demonstrated that the TGO formation has a larger effect on the durability of TBCs with denser top coat, due to its lower train tolerance [24, 39]. As described above, the porosity of the as-received top coat was lower than typical APS ones. For this reason, attention is focused on the influence of bond coat composition on the TGO formation in this section. Fig. 5 shows the thicknesses of the TGO (including $\mathrm{Al}_{2} \mathrm{O}_{3}$ and spinel oxide) formed on the bond coats as a function of cycle number. The TGO growth rate for the $\mathrm{NiAl}$ bond coat was highest, which had an average thickness of $\sim 10.5 \mu \mathrm{m}$ after 17 cycles. With $\mathrm{Lu} / \mathrm{Hf}$ doping, the oxidation rate of the $\mathrm{NiAl}$ bond coat was reduced. For example, the NiAl-Hf bond coat exhibited a lowest TGO growth rate $(\sim 7 \mu \mathrm{m}$ after 17 cycles), and that of the NiAl-Lu was slightly higher $(\sim 8.5 \mu \mathrm{m})$. This result was consistent with previous studies on the Lu/Hf doped-NiAl alloys, in which both Lu 
and Hf addition decreased the TGO growth rate [20]. For the NiCoCrAlY bond coat, though containing $\mathrm{Y}$, it showed a high oxidation rate ( 9.6 $\mu \mathrm{m}$ after 17 cycles). This was due to the formation of spinel oxide which grows more quickly than $\mathrm{Al}_{2} \mathrm{O}_{3}$ [40], as evidenced in Fig. 3. Compared with NiAl (31.5 wt.\% Al), NiCoCrAlY has a relative lower Al concentration (12 wt.\%), which tends to form $\mathrm{Ni} / \mathrm{Cr}$-rich oxide (spinel) as the quick Aldepletion [41, 42].

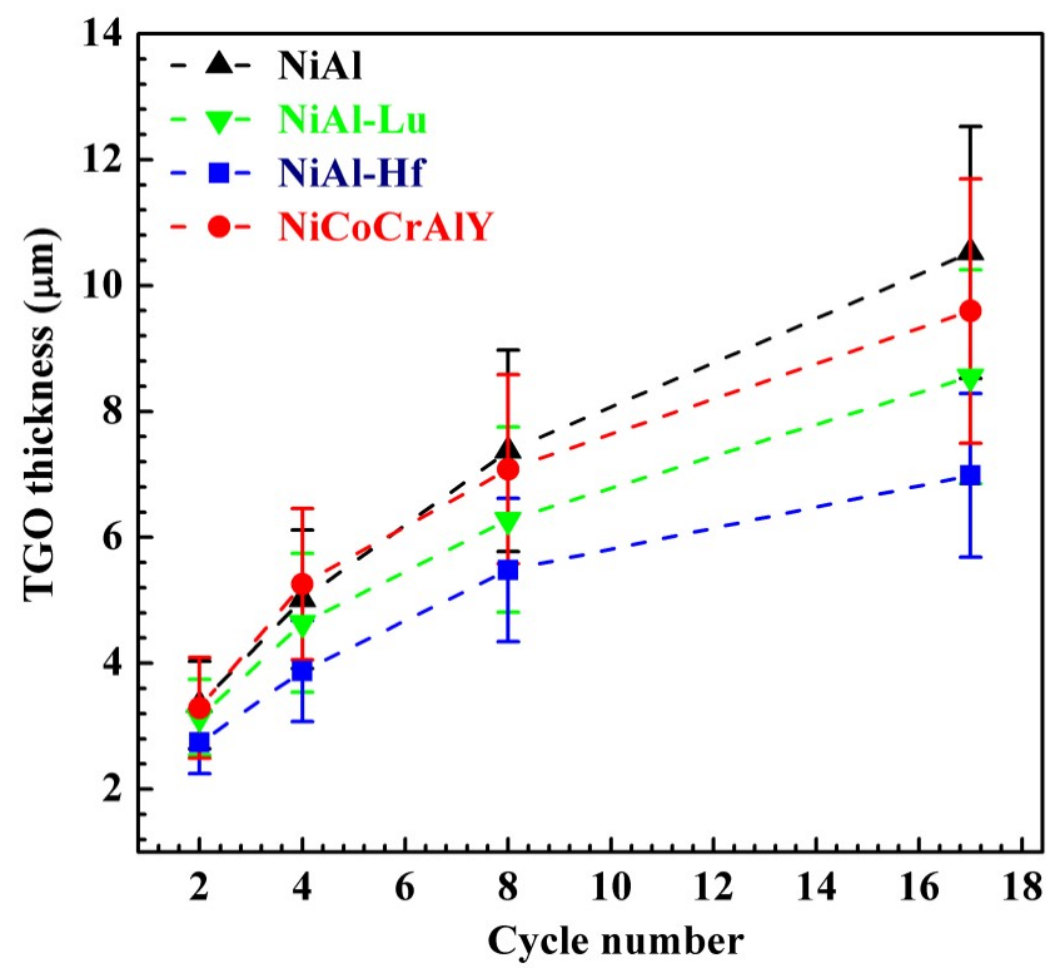

Fig. 5 The thickness of the TGO including $\mathrm{Al}_{2} \mathrm{O}_{3}$ and spinel oxide as a function of the cycle number at $1150{ }^{\circ} \mathrm{C}$.

The detailed examination of the TGO microstructure is presented in Fig. 6. For the NiAl-Lu/Hf bond coat, the TGO exhibited a dense microstructure with a lot of Lu/Hf-rich oxide precipitates. However, for the NiAl and NiCoCrAlY bond coats, a large amount of pores and cracks existed within the TGO or at the interface between the TGO and the bond coat or YSZ top coat. These defects provided rapid transport paths for oxygen, which resulted in a higher oxidation rate. 

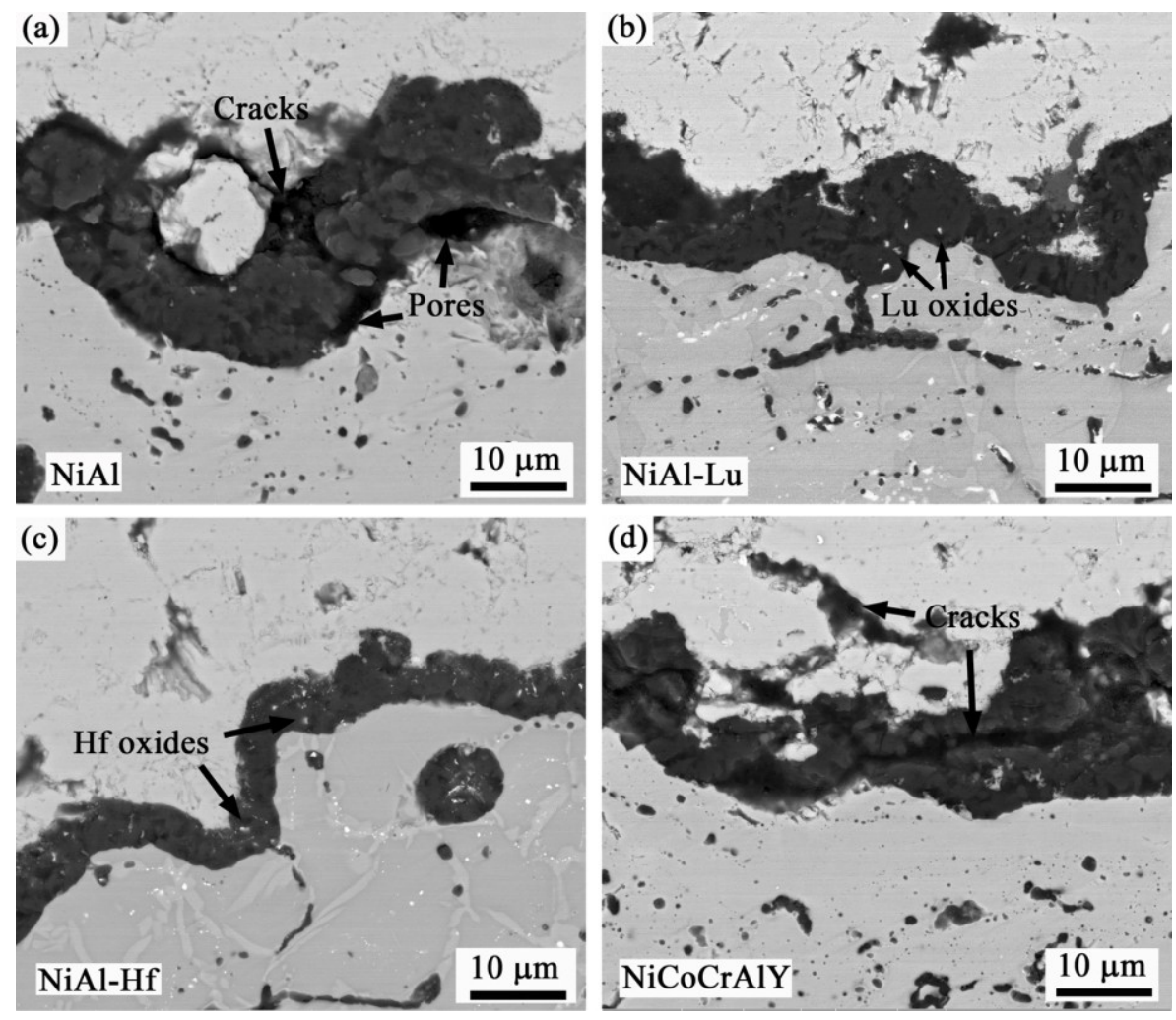

Fig. 6 Cross-sectional micrographs showing the TGO microstructure after 17 cycles at $1150{ }^{\circ} \mathrm{C}$ : (a) NiAl, (b) NiAl-Lu, (c) NiAl-Hf and (d) NiCoCrAlY

\subsection{The TBCs lifetime}

To evaluate the durability of the TBCs with different bond coats, 24-hour thermal cycling was conducted at $1150{ }^{\circ} \mathrm{C}$. The thermal cycling lifetimes $(>20 \%$ TBC spallation) of the TBCs are summarized in Fig. 7, together with the TGO thicknesses upon failure. It is visible that there was a large difference in the lifetimes of the TBCs with different bond coats. The reference sample NiCoCrAlY TBC exhibited a lifetime of $20 \pm 2$ cycles, and that of the NiAl TBC was slightly shorter ( $19 \pm 1$ cycles). Compared with the NiAl and NiCoCrAlY TBCs, the lifetimes of the NiAl-Lu and NiAl-Hf TBCs were significantly extended. For example, the TBC lifetime with the NiAl-Hf bond coat was more than 2.5 times that with the NiCoCrAlY bond coat ( $52 \pm 2$ cycles), and that with the Nile-Lu bond coat was also substantially enhanced ( $35 \pm 2$ cycles). In addition, a clear correlation between the TBC lifetime and the TGO growth rate was confirmed, i.e., the TBC lifetime decreased with a increase in the TGO growth rate. For example, the NiAl TBC exhibited the highest TGO growth rate, 
while had a shortest lifetime; and the longest lifetime was found in the NiAl-Hf TBC, which had the slowest TGO growth rate.

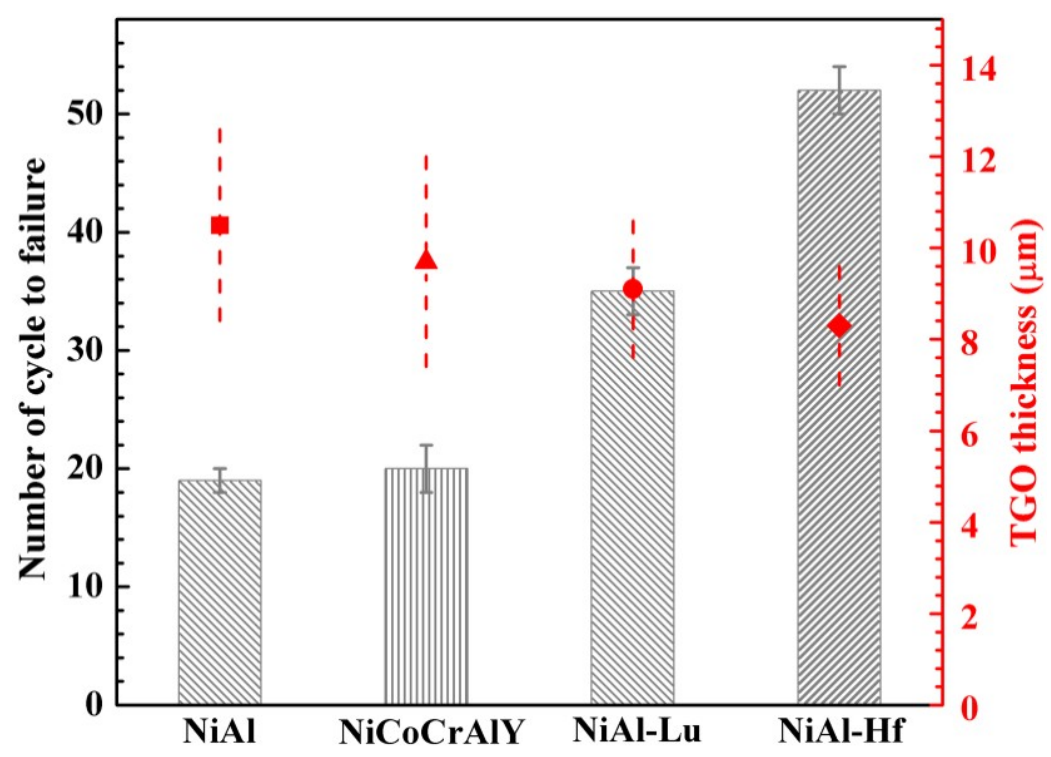

Fig. 7 The TBC lifetime (24-hour cycle) vs. the TGO thickness upon failure, illustrating a clear correlation that the $\mathrm{TBC}$ lifetime decreased with a increase in the TGO growth rate.

\subsection{Evolution of the top coat/TGO interface roughness}

It is widely accepted that the top coat/bond coat interface roughness plays a key role in APS TBC's lifetime [28, 43]. During thermal exposure, the top coat/bond coat interface roughness would increase, mainly due to rumpling of the bond coat surface along with the TGO layer. Fig. 8 presents the top coat/TGO interface roughness as a function of the cycle number. Compared with the NiCoCrAlY TBC $(\sim 12.9 \mu \mathrm{m})$, the $\mathrm{NiAl}(-\mathrm{Lu} / \mathrm{Hf})$ TBC had a slightly higher interface roughness $(\sim 13.2 \mu \mathrm{m})$ in the as-received state. For all the TBCs, the top coat/TGO interface roughness increased continuously until failure. After 17 thermal cycles, the NiCoCrAlY TBC exhibited a small increase $(0.8 \mu \mathrm{m})$ in the interface roughness. However, the interface rumpling rate for the $\mathrm{NiAl}(-\mathrm{Lu} / \mathrm{Hf}) \mathrm{TBC}$ was much higher $(1.8 \mu \mathrm{m}, 1.4 \mu \mathrm{m}$ and $1.3 \mu \mathrm{m}$ for $\mathrm{NiAl}$, NiAl-Lu and NiAl-Hf respectively, after 17 cycles). Upon failure, the interface roughness of the NiAl-Lu TBC increased to $15.1 \mu \mathrm{m}$ (35 cycles, 13.5\%), and that of the NiAl-Hf TBC increased to $15.6 \mu \mathrm{m}$ (52 cycles, $18.2 \%)$. 


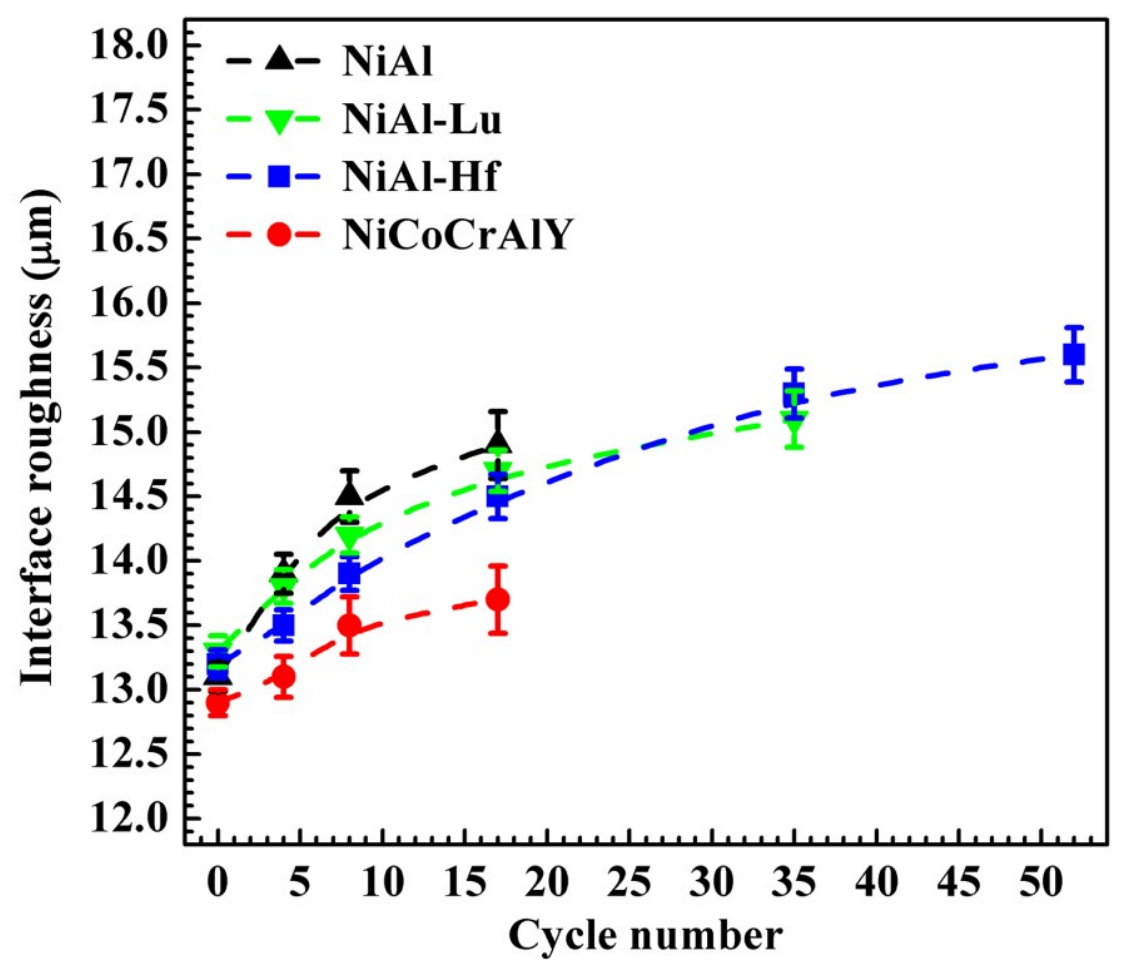

Fig. 8 Top coat/TGO interface roughness as a function of cycle number at $1150{ }^{\circ} \mathrm{C}$.

There are several factors which could affect the bond rumpling rate: (a) the coefficient of thermal expansion (CTE) of the bond coat, (b) the TGO growth rate, and (c) the mechanical properties of the bond coat. Compared with NiAl $\left(\sim 15.8 \times 10^{-6} / \mathrm{K}\right)$, NiCoCrAlY $\left(19.3-20.3 \times 10^{-6} / \mathrm{K}\right)$ has a higher CTE [44], which would result in a larger CTE mismatch stress, thus promoting the interface rumpling. However, the lower rumpling rate of the NiCoCrAlY TBC indicated this was not the primary factor influencing the interface roughness. Compared with NiAl, NiCoCrAlY has higher mechanical properties at elevated temperate (yield strength and creep resistance), which should be attributed to the less rumpling of the NiCoCrAlY bond coat [5]. With $\mathrm{Lu} / \mathrm{Hf}$ doping, the rumpling rate of the NiAl bond coat was slightly decreased (NiAl $>$ NiAl-Lu>NiAl-Hf). Previous studies have shown that $\mathrm{Hf}$ and other Heusler-forming elements significantly improve the creep resistance of $\mathrm{NiAl}[45,46]$. In Fig. 2, it was found that the distributions of $\mathrm{Lu}$ and $\mathrm{Hf}$ in NiAl were different, where Lu primarily situated within the grains as granular precipitates, while Hf mainly existed along the splat and grain boundaries. However, it is difficult to determine the influence of $\mathrm{Lu} / \mathrm{Hf}$-precipitates distributions on the creep resistance of 
the NiAl bond coat, as the creep mechanism of NiAl is strongly dependent on temperature and stress [45]. In addition, with Lu/Hf doping, the TGO growth rate of the NiAl bond coat was also decreased, which might result in a lower TGO growth stress, thus decreasing the rumpling driving force.

\subsection{The failure mode of the TBCs}

The above results confirm that the chemistry of the bond coat has a significant influence on the TBC's lifetime, so it is of great necessity to examine the influence of bond coat chemistry on the mode of TBC's failure. Fig. 9 shows the top surface optical micrographs of the failed TBCs, and their oxide structures and distributions are presented in Fig. 10.

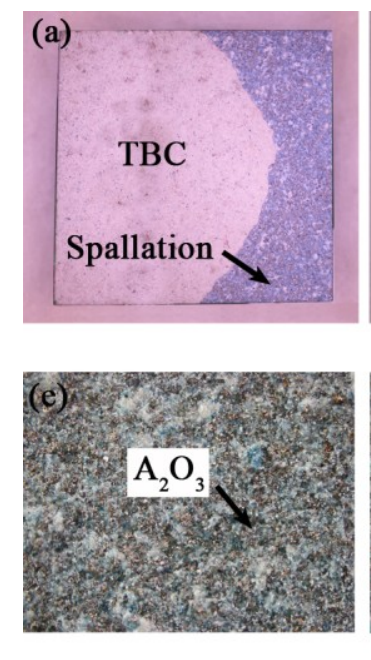

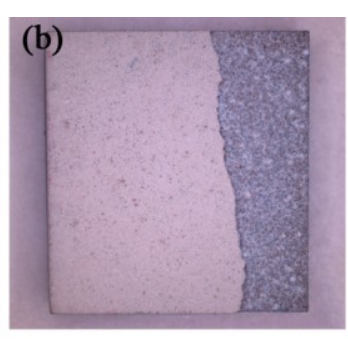

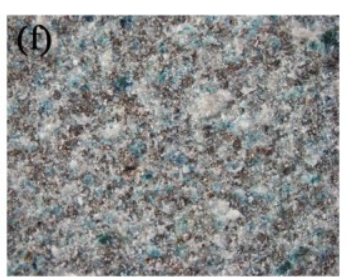

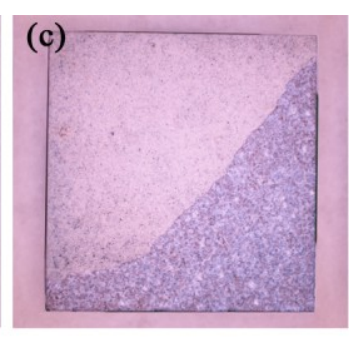

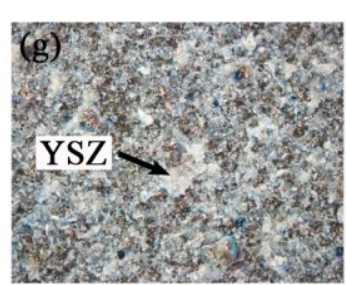

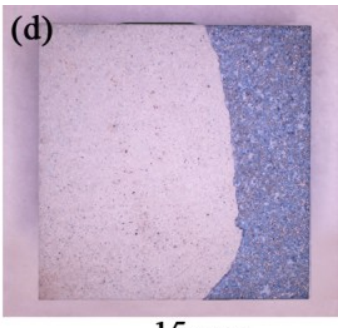

$15 \mathrm{~mm}$

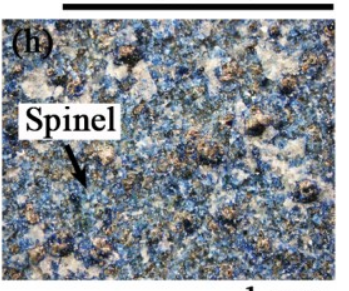

$1 \mathrm{~mm}$

Fig. 9 Top surface optical micrographs of the failed TBCs with: (a) NiAl bond coat, (b) NiAl-Lu bond coat, (c) NiAl-Hf bond coat and (d) NiCoCrAlY bond coat. (e-f) are the correspond ingly enlarged images of the spalled areas in (a-b).

It is visible that all the TBCs failed by edge delamination, while their interfacial failure (cracking) positions varied with the chemistry of the bond coats. Both the YSZ and TGO existed as residues on the bond coat surfaces for the failed TBCs, while their relative contents were in large difference, corresponding to the different failure positions. For example, a lot of separated areas representing exposed metal surface appeared on the NiAl bond coat, and the YSZ residue was rarely observed, indicating a primary failure at the $\mathrm{TGO} /$ bond coat interface. Conversely, there were a large 
amount of YSZ residues on the NiAl-Hf bond coat surface, and the area of exposed metal was rarely found, suggesting a primary failure in the top coat. In addition, a large amount of spinel residues appeared on the NiCoCrAlY bond coat surface, which was much less evident on the other samples.
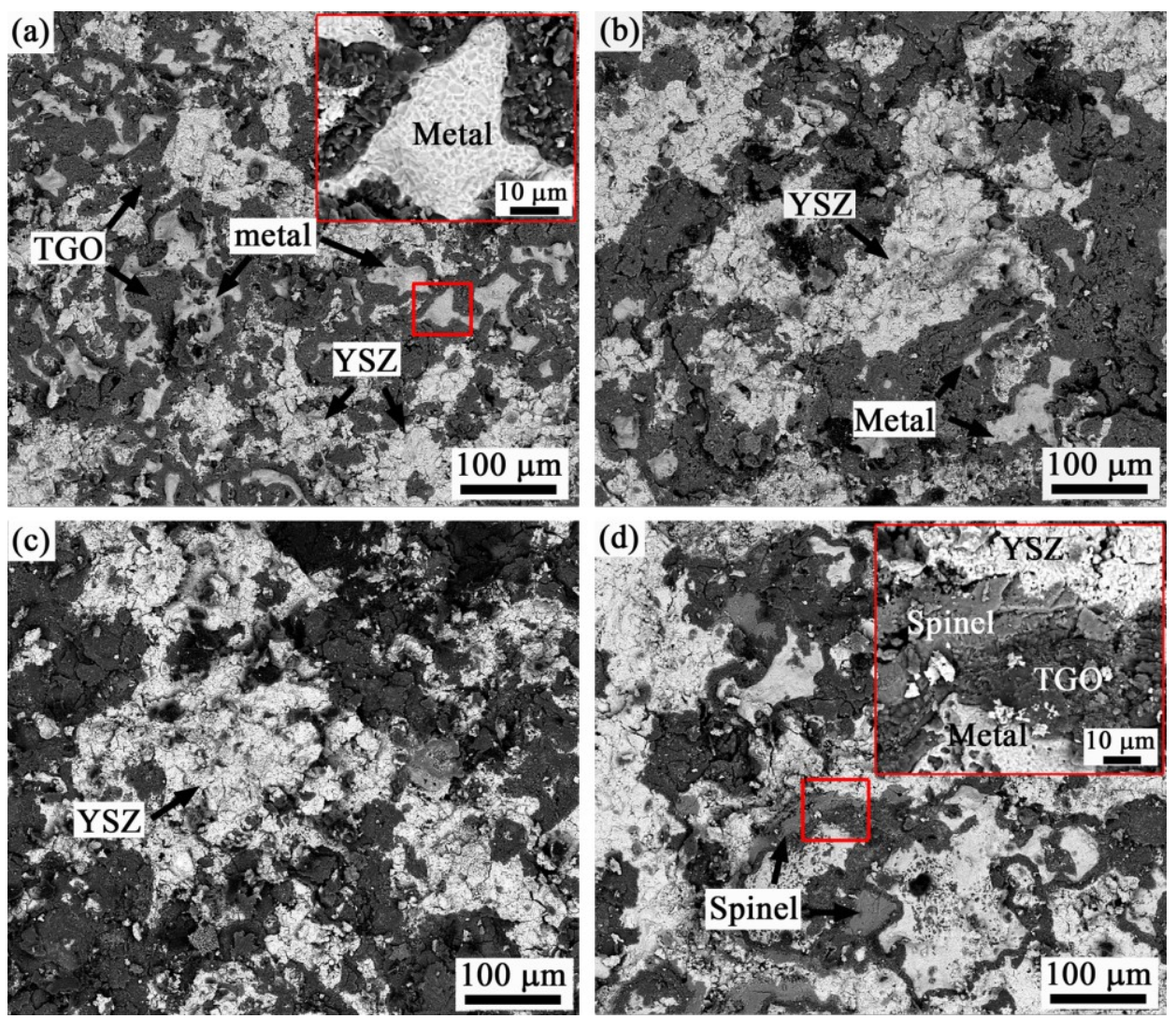

Fig. 10 Top surface SEM micrographs of the failed TBCs with: (a) NiAl bond coat, (b) NiAl-Lu bond coat, (c) NiAl-Hf bond coat and (d) NiCoCrAlY bond coat. The large and brightest residues with a lot of cracks are YSZ, the small and bright pieces with grain imprinted surfaces represent exposed metal, the $\mathrm{Al}_{2} \mathrm{O}_{3}$ oxide appears dark and spinel oxide gray.

Cross-sectional micrographs of the TBCs when interface delamination occurred are presented in Fig. 11. It is visible that the failure positions of the TBCs with different bond coats were in large differences. For the NiAl TBC, a large a mount of cracks and pores existed in the TGO, which provided preferred positions for interfacial separation. For the NiCoCrAlY TBC, typical repeated cracks formed in the TGO due to repeated cracking and growth, which are commonly observed on the plasma sprayed TBCs with MCrAlY-type bond coats [47]. For the NiAl-Lu TBC, interfacial 
delamination primarily occurred in the $\mathrm{TGO}$ and at the $\mathrm{TGO} /$ top coat interface. Though the details in the failure behavior of these three TBCs were slightly different, they all primarily failed in the TGO. However, for the NiAl-Hf TBC, the situation was totally different that delamination primarily occurred in the top coat rather than in the TGO, which is clearly shown in Figs. 11 and 12. In conclusion, the failure positions of the TBCs were significantly influenced by the bond coat compositions, i.e., the longer lifetime TBCs tended to fail in the top coat (NiAl-Hf) or at the TGO/TBC interface (NiAl-Lu), while the shorter lifetime ones preferred to fail in the TGO or at the bond coat/TGO interface (NiAl and NiCoCrAlY).
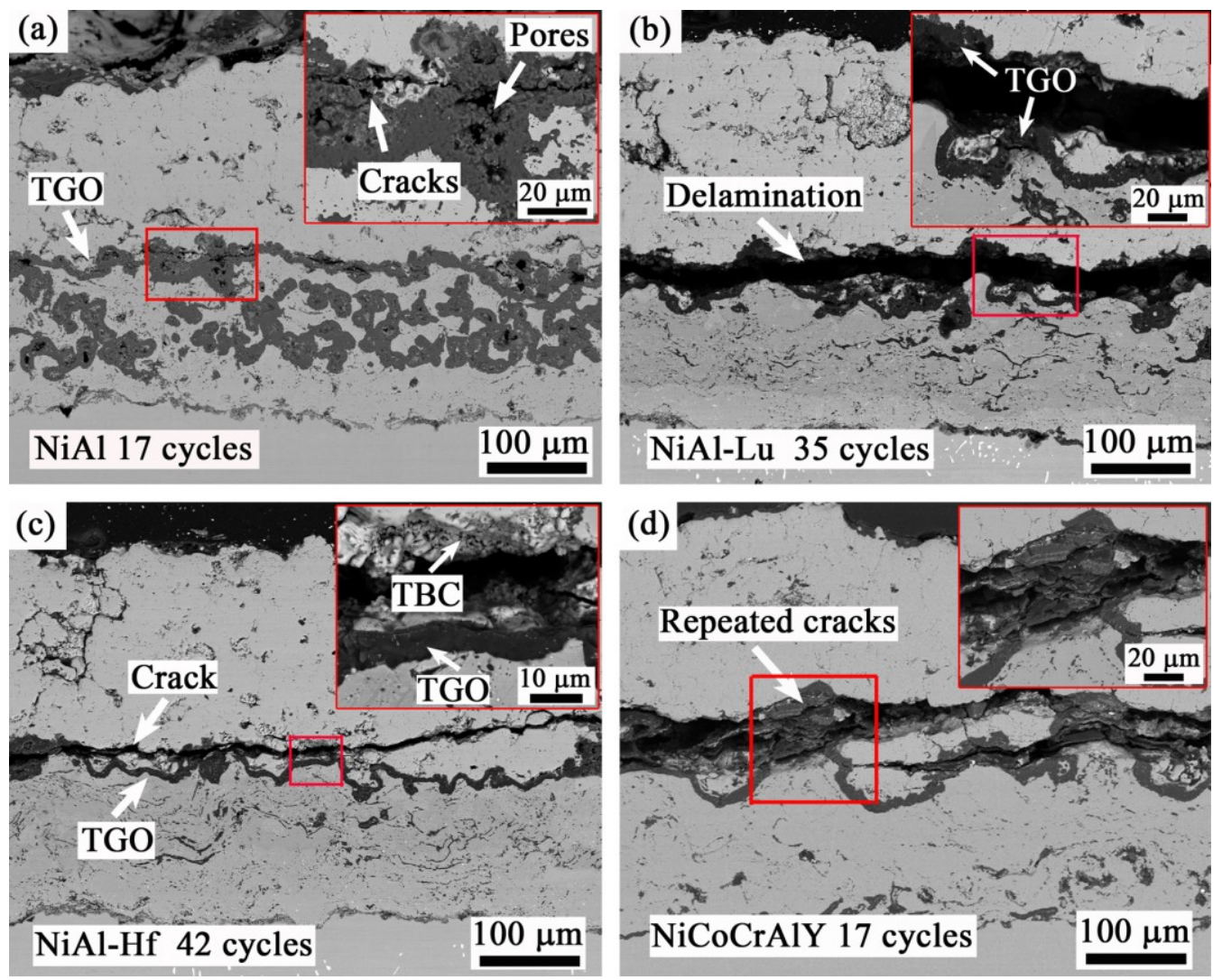

Fig. 11 Cross-sectional micrographs of the TBCs after thermal cycling at $1150{ }^{\circ} \mathrm{C}$ with: (a) NiAl bond coat, (b) NiAl-Lu bond coat, (c) NiAl-Hf bond coat and (d) NiCoCrAlY bond coat. The arrows indicate the characteristic locations such as the TGO and interfacial cracks. 


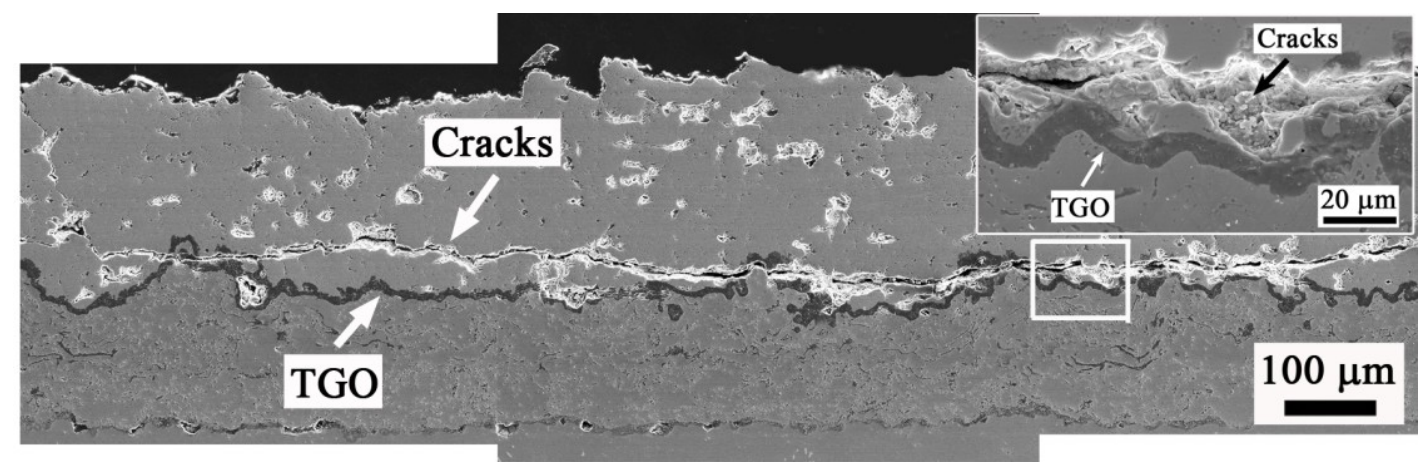

Fig. 12 Cross-sectional micrograph showing the pattern of cracks in the top coat observed on the NiAl-Hf TBC after 42 cycles.

\section{Discussion}

The results presented here demonstrate that the bond coat chemistry has a significant influence on the performance of APS TBC system. According to the established theory, the primarily driving force for TBCs failure mainly comes from the mismatch stresses induced by the difference in the coefficients of thermal expansion (CTE) between the components. However, the manner in which these stresses are relaxed depends on the specific materials properties and thermal history (isothermal or cycled) $[5,48]$.

Delamination at the bond coat/TGO interface occurs when the stored strain energy release rate $G$, exceeds the interfacial fracture toughness, $\Gamma_{(B C / T G O)}$. For a thin TGO layer of thickness $h$ on a thick substrate, the associated energy release rate is $[5,6]$ :

$$
G=\frac{1}{2}\left(\frac{1-v^{2}}{E}\right) \sigma_{o}^{2} h
$$

where $E$ and $v$ are the Young' modulus and Poisson' ratio of the TGO respectively, and $\sigma_{o}$ the stress induced by the CTE mismatch, which is approximately [49]:

$$
\sigma_{o}=\frac{E}{1-v} \Delta \alpha \Delta T
$$

where $\Delta \alpha$ is the difference in the CTE between the TGO and the substrate, and $\Delta T$ is the temperature drop upon cooling. Assuming the elastic strain energy density is 
constant through the thickness, the driving force scales linearly with the TGO thickness $h$, and hence parabolically with the oxidation time, $t$. During thermal cycling, a rapid growing TGO is suggested to accelerate the accumulation of delamination driving force. In addition, as the TGO thickens, the nature of the stresses at the bond coat/top coat interface reverses, due to a phenomenon known as stress-conversion, leading to crack initiation in the top coat at regions above the valleys [50, 51], as evidenced in Fig. 11.

On the other hand, the bond coat/TGO interfacial toughness, decreases with the increase of the exposure time as the impurities segregate to the interface and the imperfections grow $[6,49,52]$. This is due to the sensitivity of the interfacial toughness to impurity elements in the bond coat and substrate which diffuse to the bond coat/TGO interface and/or are incorporated into the TGO. For example, some nonmetallic impurities, especially $\mathrm{S}$, diffuse rapidly to the bond coat/TGO interface at high temperature, which accelerate the formation of interfacial pores, leading to degradation of interfacial toughness [36, 37]. While the harmful effect of S can be effectively eliminated by the presence of REs, such as $\mathrm{Hf}, \mathrm{Lu}$, which prevents $\mathrm{S}$ from segregating to the interface by tying up $\mathrm{S}$ in stable compounds [20,37]. As evidenced in Fig. 6, the TGO of the NiAl-Lu and NiAl-Hf TBCs exhibited a dense microstructure with the absence of cracks and pores. The kinetics of the degradation of $\Gamma_{(B C / T G O)}$ with exposure time is still open to debate, while a parabolic kinetics might be reasonable.

The situation is envisaged in Fig. 13a, which is a schematic illustration of the evolution of the delamination driving force $G$ and the interfacial toughness $\Gamma_{(B C / T G O)}$ as a function of cycle number. Initially, to a first-order approximation and for any choice of bond coat, $\Gamma_{(B C / T G O)}$ should be approximately equal for all the TBCs, considering the identical preparation parameters. However, with increasing time, it decreases - rapidly for the NiAl and NiCoCrAlY TBCs, but slowly for the NiAl-Lu and NiAl-Hf ones. As the TBC system is exposed and cycled, the driving force 
eventually exceeds the interfacial toughness, leading to final failure. This mode can well explain the failure pattern that primarily occurs at the bond coat/TGO interface, which is mainly associated with the TGO growth and degradation of the interface toughness. For example, both experiment results and Fig. 11a confirm a clear correlation between the TBC lifetime and the TGO growth rate, i.e., the TBC lifetime decreased with a increase in the TGO growth rate. As a result, the TBCs failed with different TGO thicknesses, i.e., the longer lifetime TBC failed with a smaller TGO thickness, and vice versa (Fig. 7).

(a) $\Gamma$ : Interfacial Fracture Toughness

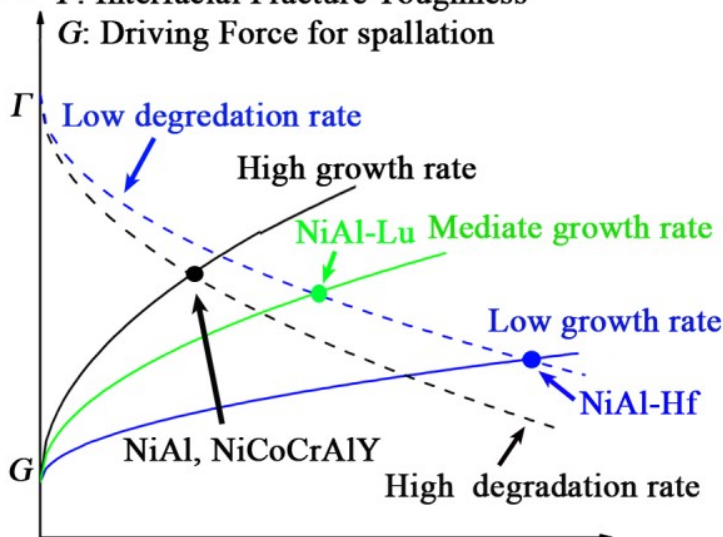

Cycle number (b)

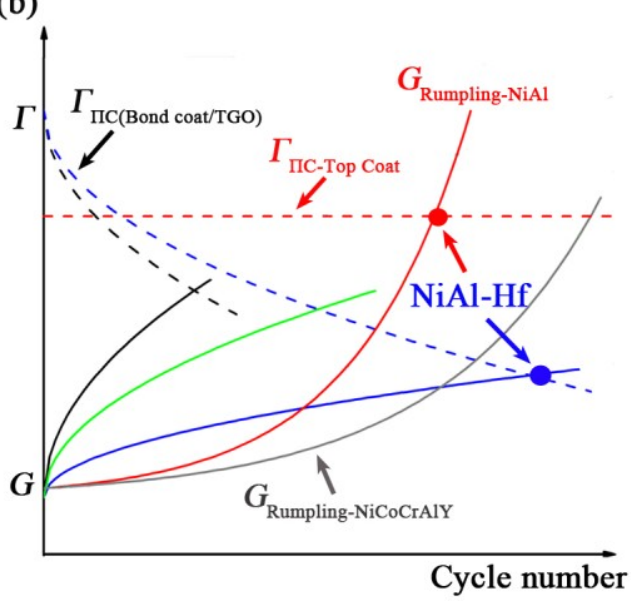

Fig. 13 Schematic illustrations of the evolution of the delamination driving force (solid lines) and interfacial fracture toughness (dashed lines) with the number of thermal cycles: (a) at the bond coat/TGO interface (b) competition of two failure mechanisms, i.e., at the bond coat/TGO interface and in the top coat. A transition from failure at the bond coat/TGO interface to failure in top coat occurs only when both the the TGO growth and degradation of the bond coat/TGO interfacial toughness are suppressed.

However, such model does not consider the situation when the TBC failure occurs in the top coat, e.g., the case for the NiAl-Hf sample. This indicates a second failure mechanism is at play. Failure in the top coat is most commonly observed in the systems with rumpled bond coats. Previous studies have demonstrated that when the bond coat rumples, out-of-plane stress develops, which is compressive above peaks and tensile above valleys along the wavy interface [5]. As a result, cracks nucleate in 
the top coat at the regions above valleys. It is demonstrated that when the driving force for mode II crack propagation exceeds the mode II fracture toughness of the top coat, $\Gamma_{\Pi \text {-Top coat }}$, the TBC failure occurs [53]. The rumpling delamination driving force, $G_{\text {Rumpling }}$, can be expected as follow [6]:

$$
G_{\text {Rumpling }}=A \times \exp (B \times N)
$$

where $A \propto E_{T B C} \times L \quad\left(E_{T B C}\right.$ is the elastic modulus of the top coat and $L$ is the undulation wavelength) and $B$ is a constant, which decreases with increasing bond coat yield strength and creep resistance, and increases with increasing TGO growth stress and bond coat CTE [53]. In section 3.5, it was found that the rumpling rate of the bond coat surface was mainly affected by the mechanical properties of the bond coat. Compared with NiCoCrAlY, NiAl has lower yield strength and creep resistance at elevated temperature, which results in a rapid increase of rumpling delamination driving force for the TBCs with NiAl-type bond coats.

Unlike the toughness at the bond coat/TGO interface, the top coat toughness, $\Gamma_{\Pi-t o p c o a t}$ is supposed to be a constant with the exposure time [6]. The situation is then envisaged in Fig.11b, where the TBC lifetime can be predicted as the intersection of the rumpling delamination driving force curve with the top coat toughness curve. By comparing the time dependence of the two failure mechanisms in Fig.13b, the measured TBCs lifetimes can be rationalized and the related failure modes can be understood. For example, the NiCoCrAlY TBC exhibited a lowest increasing rate of interface roughness, while its lifetime was shorter due to the poor TGO adherence and high TGO growth rate. In addition, both the NiAl-Lu and NiAl-Hf TBCs possessed high toughness at the bond coat/TGO interface, while large differences in their failure modes and lifetimes were found, which were mainly attributed to the difference in their TGO growth rates. Compared with the NiAl-Lu TBC, the NiAl-Hf TBC had a lower TGO growth rate (Fig. 5), which decreased the tendency of failure in the TGO, and as the cycle number increased, the NiAl-Hf TBC primarily failed in the top coat 
due to bond coat rumpling (a 18.2\% increase in interface roughness).

In fact, there are several other factors which may influence the TBCs durability, e.g., the CTE and internal oxidation of the bond coat. Compared with NiAl, the NiCoCrAlY has a higher CTE [44], which might result in a higher stress in the vicinity of the TGO upon cooling, thereby promoting the crack initiation and propagation. The internal oxidation of the bond coat, when occurs, might affect the durability of the TBC systems. For example, the large local volume expansion induced by non-uniform oxidation, especially near the bond coat/top coat interface, could change the interface morphology and induce interface cracking [30]. This might be a possible reason for the shortest lifetime of the NiAl TBC.

This study demonstrated that the APS TBC with NiAl-Lu/Hf bond coat reveled substantially enhanced lifetime during thermal cycling, which has a great potential to replace the conventional NiCoCrAlY TBC. In addition, though NiAl is a brittle material at room temperature, the NiAl-Lu/Hf bond coat was very dense and no crack was observed within the bond coat and at the bond coat/superalloy interface. However, as the bond coat fabricated by APS technique is intrinsically porous, the internal oxidation within the bond coat and/or oxidation at the bond coat/superalloy interface may hinder its application. The bond coat/superalloy interfacial morphologies of the TBCs after 17 thermal cycles and their respective EDS mapping results are presented in Fig. 14. During thermal exposure, a Ti-Al-N-O layer (predominant TiN, with some $\mathrm{Al}_{2} \mathrm{O}_{3}$ and $\mathrm{AIN}$ ) formed at the bond coat/superalloy interface, due to internal oxidation and nitridation, which has been demonstrated by previous studies [54, 55]. An effective approach to overcome base material oxidation while maintaining high bond coat roughness required for the TBC-adhesion is the use of double-layered bond coats $[27,43]$. For example, Nowak et al. [43] demonstrated that the lifetime of APS TBCs with HVOF bond coat can be substantially extended by application of a thin APS "flashcoat" layer onto the base HVOF bond coat. To further extend the lifetime of APS TBC system, a double-layered bond coat, i.e., an inner HVOF layer (NiCoCrAlY and NiAl) and an outer APS layer (NiAl-Hf) need be prepared and studied in future. 


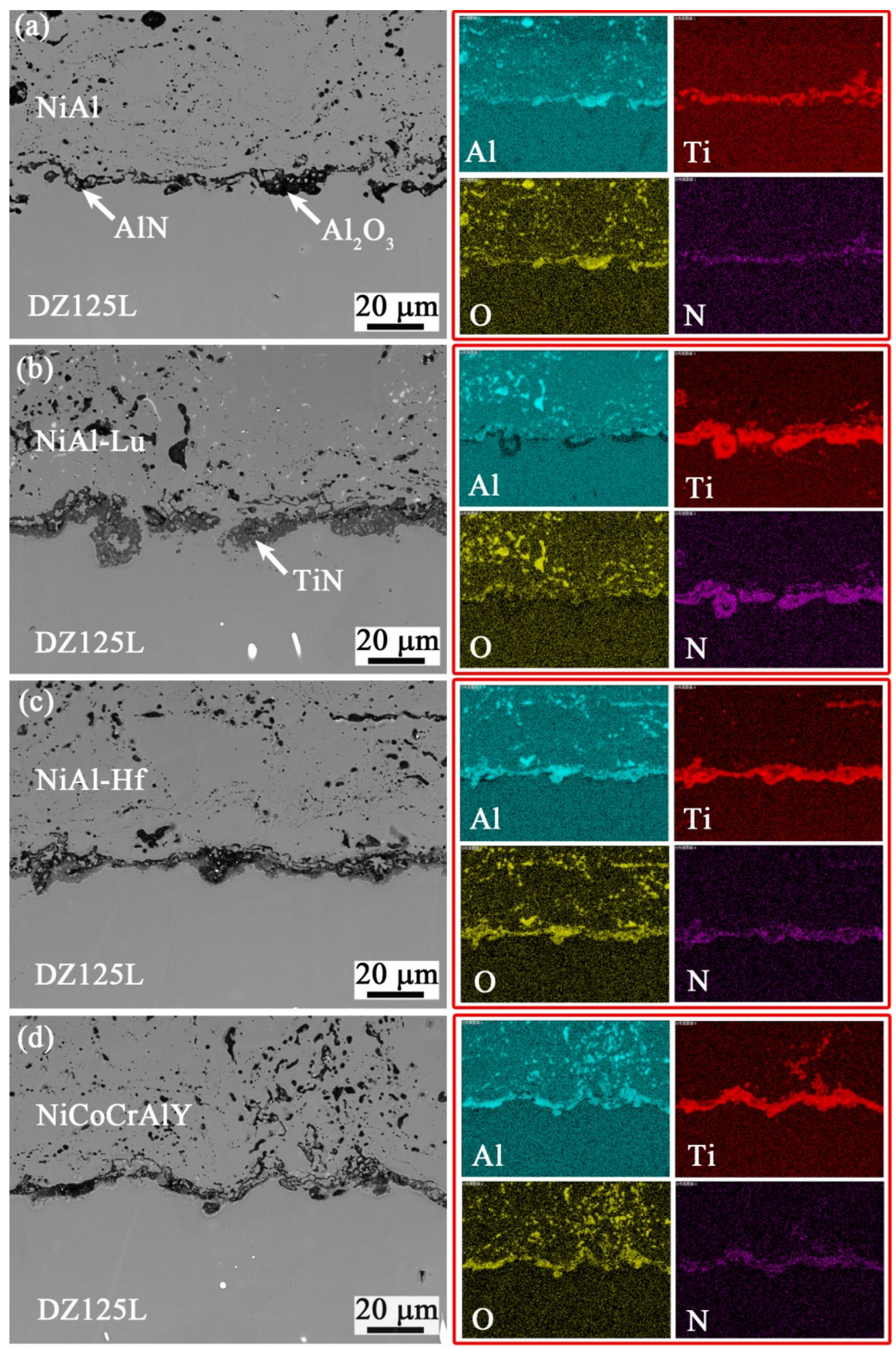

Fig. 14 Cross-sectional micrographs showing the interfacial morphologies between the superalloy and bond coat after 17 thermal cycles: (a) NiAl, (b) NiAl-Lu, (c) NiAl-Hf and (d) NiCoCrAlY. The corresponding elemental mappings were also given in the right images. 


\section{Conclusion}

In this study, the oxidation performance and durability of APS TBCs with different bond coats were investigated. The main conclusions can be drawn as follows:

(1) Compared with the TBC with conventional NiCoCrAlY bond coat, the NiAl TBC has a comparable lifetime. Doping Lu/Hf into the NiAl bond coat significantly extended the TBC lifetime. For example, the TBC lifetime with the NiAl-Hf bond coat is more than 2.5 times that with NiCoCrAlY bond coat, and that of the NiAl-Lu sample is also substantially enhanced.

(2) The NiAl bond coat suffered severe internal oxidation, which was much less obvious for the RE(Lu, Hf and Y)-containing bond coats. It is suggested that RE could suppress the internal oxidation of the bond coat by forming slowly growing and adherent oxide, as well as the case for the TGO formed on the bond coat surface.

(3) The significant enhancement of TBC lifetime with the NiAl-Lu/Hf bond coat is attributed to the combination of decreasing of the TGO growth rate and retention of the interfacial toughness, both of which are ascribed to the beneficial effects of RE.

(4) To extend the TBC lifetime, improving the TGO spallation resistance is the first importance. While for the TBC systems already possessing high TGO spallation resistance, it may be more important to decrease the rumpling rate than to further improve the TGO adherence.

\section{Acknowledgement}

This work was supported by the Baotou-SJTU innovation guidance fund project, the National Natural Science Foundation of China (Grant No. 51402058), and CNPEC financial support (Grant No. 007-EC-B-2014-C83-PS10-00065).

\section{References}

[1] N.P. Padture, M. Gell, E.H. Jordan, Thermal barrier coatings for gas-turbine engine applications, Science 296 (2002) 280-284.

[2] Y. Chen, X. Zhao, M. Bai, L. Yang, C. Li, L. Wang, J. Carr, P. Xiao, A mechanistic 
understanding on rumpling of a NiCoCrAlY bond coat for thermal barrier coating applications, Acta Mater. 128 (2017) 31-42.

[3] D.R. Clarke, C.G. Levi, Materials Design for the Next Generation Thermal Barrier Coatings, Annu. Rev. Mater. Res. 33 (2003) 383-417.

[4] K.M. Doleker, A.C. Karaoglanli, Comparison of oxidation behavior of YSZ and $\mathrm{Gd}_{2} \mathrm{Zr}_{2} \mathrm{O}_{7}$ thermal barrier coatings (TBCs), Surf. Coat. Technol. 318 (2017) 198-207.

[5] A.G. Evans, D.R. Mumm, J.W. Hutchinson, G.H. Meier, F.S. Pettit, Mechanisms controlling the durability of thermal barrier coatings, Prog. Mater. Sci. 46 (2001) 505-553.

[6] R.W. Jackson, D.M. Lipkin, T.M. Pollock, Thermal barrier coating adherence to Hf-modified B2 NiAl bond coatings, Acta Mater. 80 (2014) 39-47.

[7] P. Song, D. Naumenko, R. Vassen, L. Singheiser, W.J. Quadakkers, Effect of oxygen content in NiCoCrAlY bondcoat on the lifetimes of EB-PVD and APS thermal barrier coatings, Surf. Coat. Technol. 221 (2013) 207-213.

[8] D.R. Mumm, A.G Evans, I.T. Spitsberg, Characterization of a cyclic displacement instability for a thermally grown oxide in a thermal barrier system, Acta Mater. 49 (2001) 2329-2340.

[9] T.N. Rhys-Jones, Coatings for blade and vane applications in gas turbines, Corros. Sci. 29 (1989) 623-646.

[10] D. Li, H. Guo, H. Peng, S. Gong, H. Xu, Improved alumina scale adhesion of electron beam physical vapor deposited Dy/Hf-doped $\beta$-NiAl coatings, Appl. Surf. Sci. 283 (2013) 513-520.

[11] R.D. Noebe, R.R. Bowman, M.V. Nathal, Physical and mechanical properties of the B2 compound NiA1, Int. Mater. Rev. 38 (2013) 193-232.

[12] I. Baker, A review of the mechanical properties of B2 compounds, Mater. Sci. Eng. A 192-193 (1995) 1-13.

[13] D. Wang, H. Peng, S. Gong, H. Guo, NiAlHf/Ru: Promising bond coat materials in thermal barrier coatings for advanced single crystal superalloys, Corros. Sci. 78 (2014) 304-312.

[14] D. Prajitno, B. Gleeson, D.J. Young, The cyclic oxidation behaviour of $\alpha-\mathrm{Cr}+$ $\beta$-NiAl alloys with and without trace Zr addition, Corros. Sci. 39 (1997) 639-654.

[15] B.A. Pint, L.W. Hobbs, The Oxidation Behavior of $\mathrm{Y}_{2} \mathrm{O}_{3}$-Dispersed $\beta$-NiAl, Oxid. Met. 61 (2004) 273-292.

[16] S. Hamadi, M.P. Bacos, M. Poulain, S. Zanna, A. Seyeux, V. Maurice, P. Marcus, Oxidation of a $\mathrm{Zr}$-doped NiAl bondcoat thermochemically deposited on a nickel-based superalloy, Mater. High Temp. 26 (2014) 195-198. 
[17] Y. Zhou, X. Zhao, C. Zhao, W. Hao, X. Wang, P. Xiao, The oxidation performance for $\mathrm{Zr}$-doped nickel aluminide coating by composite electrodepositing and pack cementation, Corros. Sci. 123 (2017) 103-115.

[18] Y. Wang, J. Smialek, M. Suneson, Oxidation Behavior of Hf-Modified Aluminide Coatings on Inconel-718 at $1050{ }^{\circ} \mathrm{C}$, J. Coat. Sci. Technol. 1 (2015) 25-45.

[19] H. Guo, T. Zhang, S. Wang, S. Gong, Effect of Dy on oxide scale adhesion of NiAl coatings at $1200^{\circ} \mathrm{C}$, Corros. Sci. 53 (2011) 2228-2232.

[20] C. Zhao, Y. Zhou, Z. Zou, L. Luo, X. Zhao, F. Guo, P. Xiao, Effect of alloyed Lu, $\mathrm{Hf}$ and $\mathrm{Cr}$ on the oxidation and spallation behavior of NiAl, Corros. Sci. 126 (2017) 334-343.

[21] J.A. Haynes, M.K. Ferber, W.D. Porter, Thermal Cycling Behavior of Plasma-Sprayed Thermal Barrier Coatings with Various MCrAIX Bond Coats, J. Therm. Spray Technol. 9 (2000) 38-48.

[22] R.L. Orban, M. Lucaci, M. Rosso, M.A. Grande, NiAl Behavior at Plasma Spray Deposition, Mater. Sci. Forum 534-536 (2007) 1545-1548.

[23] X. Fan, L. Zhu, W. Huang, Investigation of NiAl intermetallic compound as bond coat for thermal barrier coatings on Mg alloy, J. Alloys Comp. 729 (2017) 617-626.

[24] Z. Zou, C. Xing, L. He, X. Shan, L. Luo, X. Zhao, F. Guo, P. Xiao, A highly strain and damage-tolerant thermal barrier coating fabricated by electro-sprayed zirconia hollow spheres, J. Am. Ceram. Soc. 101 (2018) 4375-4386.

[25] Y. Bai, L. Zhao, Y.M. Qu, Q.Q. Fu, Y. Wang, K. Liu, J.J. Tang, B.Q. Li, Z.H. Han, Particle in-flight behavior and its influence on the microstructure and properties of supersonic-atmospheric-plasma-sprayed nanostructured thermal barrier coatings, J. Alloys Comp. 644 (2015) 873-882.

[26] V. Viswanathan, G. Dwivedi, S. Sampath, T. Troczynski, Engineered Multilayer Thermal Barrier Coatings for Enhanced Durability and Functional Performance, J. Am. Ceram. Soc. 97 (2014) 2770-2778.

[27] Z. Zou, L. Jia, L. Yang, X. Shan, L. Luo, F. Guo, X. Zhao, P. Xiao, Role of internal oxidation on the failure of air plasma sprayed thermal barrier coatings with a double-layered bond coat, Surf. Coat. Technol. 319 (2017) 370-377.

[28] V.K. Tolpygo, D.R. Clarke, On the rumpling mechanism in nickel-aluminide coatings, Acta Mater. 52 (2004) 5129-5241.

[29] Y. Bai, Z.H. Han, H.Q. Li, C. Xu, Y.L. Xu, C.H. Ding, J.F. Yang, Structure-property differences between supersonic and conventional atmospheric plasma sprayed zirconia thermal barrier coatings, Surf. Coat. Technol. 205 (2011) 3833-3839.

[30] T. Patterson, A. Leon, B. Jayaraj, J. Liu, Y.H. Sohn, Thermal cyclic lifetime and 
oxidation behavior of air plasma sprayed CoNiCrAlY bond coats for thermal barrier coatings, Surf. Coat. Technol. 203 (2008) 437-441.

[31] J. Jiang, Z. Zou, W. Wang, X. Zhao, Y. Liu, Z. Cao, Effect of internal oxidation on the interfacial morphology and residual stress in air plasma sprayed thermal barrier coatings, Surf. Coat. Technol. 334 (2018) 215-226.

[32] X. Gong, H. Peng, Y. Ma, H. Guo, S. Gong, Microstructure evolution of an EB-PVD NiAl coating and its underlying single crystal superalloy substrate, J. Alloys Comp. 672 (2016) 36-44.

[33] B. Bai, H. Guo, H. Peng, L. Peng, S. Gong, Cyclic oxidation and interdiffusion behavior of a NiAlDy/RuNiAl coating on a Ni-based single crystal superalloy, Corros. Sci. 53 (2011) 2721-2727.

[34] X. Gong, Y. Pei, Y. Ma, S. Li, S. Gong, Interdiffusion Behavior at Interface Between NiAlHfSi Coatings and $\mathrm{Ni}_{3}$ Al Based Superalloy Sub strates, PRICM: 8 Pacific Rim International Congress on Advanced Materials and Processing (2013) 2051-2060.

[35] P. Niranatlumpong, C.B. Ponton, H.E. Evans, The Failure of Protective Oxides on Plasma-Sprayed NiCrAlY Overlay Coatings, Oxid. Met. 53 (2000) 241-258.

[36] D. Li, H. Guo, D. Wang, T. Zhang, S. Gong, H. Xu, Cyclic oxidation of $\beta$-NiAl with various reactive element dopants at $1200^{\circ} \mathrm{C}$, Corros. Sci. 66 (2013) 125-135.

[37] D. Naumenko, B.A. Pint, W.J. Quadakkers, Current Thoughts on Reactive Element Effects in Alumina-Forming Systems: In Memory of John Stringer, Oxid. Met. 86 (2016) 1-43.

[38] C. Bargraser, P. Mohan, K. Lee, B. Yang, J. Suk, S. Choe, Y.H. Sohn, Life approximation of thermal barrier coatings via quantitative microstructural analysis, Mater. Sci. Eng. A 549 (2012) 76-81.

[39] H.B. Guo, R. Vaßen, D. Stöver, Atmospheric plasma sprayed thick thermal barrier coatings with high segmentation crack density, Surf. Coat. Technol. 186 (2004) 353-363.

[40] L. Luo, X. Shan, Z. Zou, C. Zhao, X. Wang, A. Zhang, X. Zhao, F. Guo, P. Xiao, A high performance NiCoCrAlY bond coat manufactured using laser powder deposition, Corros. Sci. 126 (2017) 356-365.

[41] L. Qiu, F. Yang, W. Zhang, X. Zhao, P. Xiao, Effect of Al content on the lifetime of thermally grown oxide formed on $\mathrm{Ni}-\mathrm{Al}$ alloys after isothermal oxidation, Corros. Sci. 89 (2014) 13-20.

[42] K. Ma, J.M. Schoenung, Isothermal oxidation behavior of cryomilled NiCrAlY bond coat: Homogeneity and growth rate of TGO, Surf. Coat. Technol. 205 (2011) 5178-5185.

[43] W. Nowak, D. Naumenko, G. Mor, F. Mor, D.E. Mack, R. Vassen, L.Singheiser, 
W.J. Quadakkers, Effect of processing parameters on MCrAlY bondcoat roughness and lifetime of APS-TBC systems, Surf. Coat. Technol. 260 (2014) 82-89.

[44] J.A. Haynes, B.A. Pint, W.D. Porter, I.G. Wright, Comparison of thermal expansion and oxidation behavior of various high-temperature coating materials and superalloys, Mater High Temp. 21 (2014) 87-94.

[45] K. Oh-ishi, Z. Horita, M. Nemoto, Microstructure and strength of B2-ordered NiA1 containing L21-Ni2AlHf precipitates, Mater. Sci. Eng. A 239-240 (1997) 472-478.

[46] J.T. Guo, C.Y. Cui, Y.H. Qi, H.Q. Ye, Microstructure and elevated temperature mechanical behavior of cast NiAl-Cr(Mo) alloyed with Hf, J. Alloys Comp. 343 (2002) 142-150.

[47] D. Naumenko, V. Shemet, L. Singheiser, W.J. Quadakkers, Failure mechanisms of thermal barrier coatings on MCrAlY-type bondcoats as sociated with the formation of the thermally grown oxide, J. Mater. Sci. 44 (2009) 1687-1703.

[48] A.C. Karaoglanli, K. Ogawa, A. Turk, I. Ozdemir, Thermal Shock and Cycling Behavior of Thermal Barrier Coatings (TBCs) Used in Gas Turbines, Progress in Gas Turbine Performance (2013) 237-260.

[49] R. T. Wu, K. Kawagishi, H. Harada, R.C. Reed, The retention of thermal barr ier coating systems on single-crystal superalloys: Effects of substrate composition, Acta Mater. 56 (2008) 3622-3629.

[50] R. Vaßen, G. Kerkhoff, D. Stöver, Development of a micromechanical life prediction model for plasma sprayed thermal barrier coatings, Mater. Sci. Eng. A 303 (2001) 100-109.

[51] P. Skalka, K. Slámečka, J. Pokluda, L. Čelko, Finite element simulation of stresses in a plasma-sprayed thermal barrier coating with a crack at the TGO/bond-coat interface, Surf. Coat. Technol. 337 (2018) 321-334.

[52] R.T. Wu, 13-Substrate and bond coat related failure of thermal barrier coatings, Therm. Barrier Coat. (2011) 263-293.

[53] T. Xu, M.Y. He, A.G. Evans, A numerical assessment of the durability of thermal barrier systems that fail by ratcheting of the thermally grown oxide, Acta Mater. 51 (2003) 3807-3820.

[54] Y.Z. Liu, X.B. Hu, S.J. Zheng, Y.L. Zhu, H. Wei, X.L. Ma, Microstructural evolution of the interface between NiCrAlY coating and superalloy during isothermal oxidation, Mater. Design 80 (2015) 63-69.

[55] U. Krupp, H.J. Christ, Selective oxidation and internal nitridation during high-temperature exposure of single-crystalline nickel-base superalloys, Metall. Mater. Trans. A 31 (2000) 47-56. 